\title{
A crítica de um discurso: como puderam os jovens tornar-se protagonistas?
}

\section{The critique of a discourse: how could young people become protagonists?}

\author{
Victor Amaral Costa \\ Mestrando do Programa de Pós-graduação em Antropologia Social/Centro de Educação e \\ Ciências Humanas/Universidade Federal de São Carlos. \\ costantropos@gmail.com
}

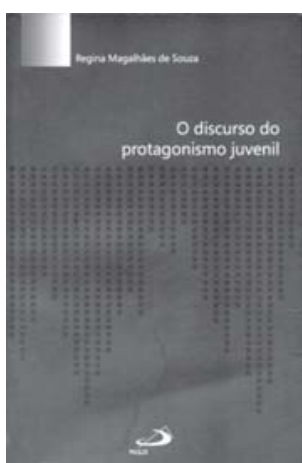

SOUZA, Regina Magalhães de. O discurso do protagonismo juvenil. São Paulo: Paulus. 2008. $216 \mathrm{p}$.
$\mathrm{T}$ odo cientista social que, nos entremeios de sua pesquisa, acabe se defrontando com a questão tão tradicional quanto polêmica da emergência do sujeito, terá a sensação de que, por mais esforços que mobilize, seu trabalho estará fadado à incompletude. É questão essencialmente complexa, que nos remete a genealogias infindáveis, conforme as correntes teóricas a que se pretende dar voz: 'sujeito' psicanalítico, 'sujeito' político, 'sujeito' econômico, 'sujeitos' cosmológicos - e assim por diante. Entretanto, parece haver ao menos uma pedra de toque que nos obriga a conceituar 'sujeito': a ação, a atuação, a atualização ou o agenciamento; enfim tudo aquilo que por e/ou através dele se coloca em movimento.

Quando a questão não é tratá-lo como eixo central sobre o qual se assentam determinadas realidades, evitando-se assim discussões complexas sobre as condições (e interesses) de seu surgimento, o sujeito é comumente obliterado pela insígnia 'ator'. Porém, tratar com seriedade tal tema dentro de nossos objetos de pesquisa nos colocaria diante de outras tantas questões ainda muito mal resolvidas em nosso métier, como por exemplo a antiga antinomia entre estrutura e prática.

Em minha pesquisa de mestrado, não consegui escapar desses enredos. Por conta de uma pesquisa a respeito da demanda por psicoterapia entre estudantes universitários, todas essas questões irromperam de uma só vez. Pois foi devido a essa necessidade de pesquisa que conheci o livro de Regina Magalhães de Souza. O discurso do protagonismo juvenil é resultado de sua pesquisa de doutorado em sociologia pela Universidade de São Paulo e sem dúvida constitui excelente atalho de fuga de qualquer 'transcendentalismo' e prolixidade referente ao 'acionamento' de tal modalidade de discurso e dos sujeitos desse discurso. Em nome do tal protagonismo juvenil, tem-se procurado construir um modelo de cidadania coerente com as exigências de um contexto neoliberal sob o qual os sujeitos são 'convidados' a ser atores das ações políticas e econômicas. A versão do 'ator inserido nesse cenário' contempla os desejos de uma política ideológica, por meio da qual seus defensores ainda 
almejam ver realizados seus ideais de um 'ativismo privado', sem abdicar, contudo, de uma ação 'consciente' e 'responsável' para com os coletivos dos quais esses indivíduos fariam parte.

Não obstante, para que esse projeto de cidadania atoral se efetive, é necessário que tal discurso possa infletir sobre uma coorte particularmente sensível a estratégias psicopedagógicas de governamentalidade (Foucault, 1981). É, portanto, na juventude - encarada como a fase de transição em que se inserirão os repertórios necessários a uma cidadania plena - que esse discurso se fará incidir com mais força. Mas não qualquer juventude; o protagonismo juvenil requer um tipo específico de ator, uma modalidade de ação, um estilo de vida:

O discurso não se apresenta como emissor da regra, apresentada como algo exterior que se aplica ao objeto do discurso. A prescrição ocorre por meio da própria atividade. É a atividade do próprio jovem protagonista, objeto de intervenção, que se encarrega de confirmar e materializar o discurso. A atividade em questão é o fazer coisas ou a oferta gratuita de bens e serviços, também nomeada trabalho voluntário. O fazer coisas ocupa o lugar da cidadania, com ela se confunde e oferece uma alternativa "saudável" de participação juvenil. Participação, cidadania e trabalho voluntário equivalem-se e são definidos, todos, pela atividade (p.15).

Esse tipo de formação discursiva revela, para a autora, uma face perversa de um projeto de cidadania que acaba por imiscuir as desigualdades engendradas por relações de poder e exploração, ao dotar exclusivamente os indivíduos da capacidade de gerar resultados eficientes em termos de política social. Uma única competência estaria sendo sobrevalorizada nas estratégias educacionais do jovem, a do ativismo privado, associado à habilidade de negociação, a qual, segundo esse 'projeto de jovem', conseguirá articular demandas particulares a projetos coletivos mais amplos.

Não é por acaso que o protagonismo juvenil vem ganhando apoio institucional e programático nas estratégias socioeducativas. Documentos da Cepal (Unesco, 2000), Unesco (2004) e mesmo dos Ministérios da Saúde e do Planejamento e Orçamento do governo brasileiro, na figura da Comissão Nacional de População e Desenvolvimento (Brasil, 1998), têm ressaltado essa nova configuração sobre o papel da juventude na sociedade atual como uma demanda endógena às suas realidades. É dessa forma que o aparente paradoxo entre individuação e integração tem sido equacionado pelos discursos institucionais sobre juventudes. Só a 'participação ativa' dos jovens poderá dar conta de transformar sua realidade. Tal concepção é ressaltada pelos estudos da Unesco, como se faz notar no trecho abaixo:

Isso é muito relevante: os jovens querem participar, e o fazem muito ativamente em certas ocasiões, mas valorizam em sentido de autonomia. De fato, muitos jovens vêm se destacando em movimentos pela ética, movimentos pela paz, e, em particular, nos movimentos críticos à globalização. Contudo, a forma de organização encontrada por essas juventudes se distancia das formas tradicionais e se interliga a concepções de interação em rede e em novas formas de participação juvenil. Nesse sentido, a importância de se escutar as pessoas jovens no momento da definição de uma política pública de juventudes não pode ser subestimada. Uma política nacional de juventude que não reflita as visões, preocupações e desejos dos jovens se distanciará de seu objetivo primordial, e com o 
tempo, cairá no esquecimento, pois não contará com apoio. Assim, políticas ou programas $\mathrm{de} /$ para/com jovens devem ser formatados a partir de seu envolvimento compreensivo, contando com espaços de participação juvenil nos processos de tomadas de decisão (Unesco, 2004, p.68-69).

É no livro de Regina M. Souza que encontramos um mapa preciso de todas as superfícies veladas por essa prática discursiva. Ressalte-se que não é intenção da autora desvendar essencialismos subjacentes nesse discurso, mas sim, como ela própria afirma, delinear "suas condições de possibilidade, contradições e ... seu movimento de articulação e transformação" (p.19), que lhe permitiram desenhar uma cartografia precisa do terreno em que esse discurso se move.

Sua geologia começa por prospectar os elementos que tornam possível e necessários a emergência desse 'novo' sujeito de cidadania, o jovem. No primeiro capítulo, a autora enfatiza que esse sujeito é novo porque, em termos históricos, é também recente, isto é, a ideia da juventude como fase de transição é uma 'invenção' necessária às sociedades industriais. Trata-se de conciliar juventude e política com a peneira ideológica do neoliberalismo. Filtradas as impurezas de um discurso exógeno dos adultos, que induz, por um lado, a ideias autoritárias de políticas tutelares e, de outro, a formas arcaicas de participação política (como partidos, movimento estudantil e seus congêneres) que não mais contemplam as 'aspirações imediatas' da juventude, só restam indivíduos 'atuando' num 'cenário' em que a habilidade de negociação é condição para o jovem vir a ser um 'sujeito' político, isto é, um 'cidadão'.

No decorrer dos segundo e terceiro capítulos, desloca-se das 'novas formas de política' que permitem identificar os sujeitos que são objetos desse discurso, isto é, a(s) juventude(s) - para os sujeitos enunciadores. Em outras palavras, a análise recai sobre a fabricação de um consenso esperado por aqueles 'atores' políticos considerados tradicionais nesse cenário, quais sejam, aqueles que tomam para si a responsabilidade da ação autônoma e independente do Estado - em geral, as ONGs. Disso decorre a importância de ressaltar as experiências do voluntariado. Nada escapa ao poder de atração de constituir uma 'ação comum' e 'transformadora' das políticas sociais voltada para as juventudes. Pois, como os grandes avatares da institucionalização desse discurso enfatizam,

\begin{abstract}
Se olharmos o protagonismo do ponto de vista da sua importância para o desenvolvimento pessoal e social do adolescente, ele é um direito. Sem esse espaço de descoberta e experimentação social, a transição para o mundo adulto será certamente mais incompleta, limitada e vazia de um certo tipo de prática e vivência fundamentais para a vida. Por outro lado, se olharmos o protagonismo do ponto de vista da família, da escola e da comunidade, não podemos deixar de percebê-lo como um dever. O chamado, a convocação ao envolvimento em questões reais da vida escolar, comunitária e social mais ampla, é antes de mais nada um apelo à consciência ética e ao compromisso cidadão do adolescente com a comunidade onde sua vida se desenvolve (Costa, Vieira, 2006, p.238).
\end{abstract}

Por mais inexplorado que o campo da juventude ainda seja para se falar de uma demanda política específica, nada autorizaria, a princípio, esse tipo de naturalização do protagonismo juvenil como necessidade imponderável para superação das vicissitudes da juventude. O que o livro de Souza acena, mas não aprofunda, é que esse discurso possibilita pensar 
numa nova acepção de pessoa (Mauss, 2003), formada por uma visão etapista e cumulativa de competências necessárias para o desenvolvimento esperado por um Estado neoliberal. Nessa perspectiva, o grande mérito da autora é oferecer um estranhamento (imprescindível à crítica) quanto a esse discurso e ponderar as possíveis consequências dele em outros campos de pesquisa que tenham de enfrentar essas mesmas naturalizações discursivas.

A apropriação do protagonismo juvenil como tática psicoterapêutica já anuncia sua inserção como critério pedagógico necessário ao bem-estar, condição 'sagrada' para pensar a cidadania. E mais: só o indivíduo é capaz de delimitar a fronteira normatizadora do que lhe é ou não necessário e/ou aprazível. No capítulo 4, "Limites e êxitos de um discurso compartilhado", a autora nos apresenta um quadro inteiramente diferente do que aquele que se desenha pelo discurso institucional. A 'emancipação' pelo protagonismo juvenil quer, na verdade, disciplinar (Foucault, 2007) o jovem para a modalidade de sujeito que se espera dele. $\mathrm{E}$ aquilo que poderia ser entendido como resistência a esse projeto de cidadania - ou seja, a recusa à ideologia do 'fazer por si próprio' - pode, consequentemente, ser alocado na chave do desvio, na ótica das instituições. Essa não é uma tendência tão nova. As condições de emergência do sujeito, antes relegada ao âmbito exclusivo da família, requereram uma intervenção tecnocrata do mercado de trabalho. Era portanto necessário, ao sujeito integrado neste cenário, um maior período de preparação educacional e dispêndio tutelar por parte de toda a sociedade. Por isso, a emergência de políticas específicas para a coorte jovem passa a se articular com estratégias de disciplinarização:

Ela designa um processo específico, possivelmente exclusivo da sociedade ocidental moderna, indissociável do 'individualismo' e da 'individualização'. Sua principal característica é o deslocamento da engrenagem de poder de uma instância superior englobante e qualitativamente distinta dos sujeitos sociais ordinários (o que caracteriza o poder soberano) para as próprias competências dos sujeitos, aos quais o poder é instauradoramente incorporado (no sentido do habitus de Bourdieu ou na da civilização de Elias) (Duarte, 1993, p.16).

A autora nos presenteia, ao final de $O$ discurso do protagonismo juvenil, com uma arguta genealogia dos preceitos que possibilitaram a naturalização do discurso do protagonismo juvenil: o imediatismo na consecução dos interesses dessa coorte, a fim de garantir um futuro promissor aos jovens; um horizonte de aprendizagem ininterrupta e infinita, que possa atualizar suas demandas particulares contiguamente aos interesses coletivos. Sem dúvida tal discurso é preponderantemente pedagógico. É necessário 'fabricar' jovens cidadãos, e é na conquista de consenso entre todos os sujeitos que ele assume a forma de verdade indiscutível:

Tratar-se-ia da genealogia de regimes veridicionais, isto é, da análise da constituição de certo direito da verdade a partir de uma situação de direito, com relação direito/verdade encontrando sua manifestação privilegiada no discurso, o discurso em que se formula o direito e em que se formula o que pode ser verdadeiro ou falso; de fato, o regime de veridição não é uma certa lei da verdade, [mas sim] o conjunto das regras que permitem estabelecer, a propósito de um discurso dado, quais enunciados poderão ser caracterizados, nele, como verdadeiros ou falsos (Foucault, 2008, p.49). 


\section{REFERÊNCIAS}

BRASIL.

Comissão Nacional de População e

Desenvolvimento. Jovens acontecendo na trilha das políticas públicas. Brasília: Ministério do Planejamento e Orçamento. 1998.

COSTA, Antonio Carlos Gomes da; VIEIRA, Maria Adenil.

Protagonismo juvenil: adolescência, educação e participação democrática. Salvador: Fundação Odebrecht. 2006.

DUARTE, Luiz Fernando D. et al.

Vicissitudes e limites da conversão à cidadania nas classes populares brasileiras. Revista Brasileira de Ciências Sociais, São Paulo, ano 8, n.22, p.5-19. 1993.

FOUCAULT, Michel.

Nascimento da biopolítica. São Paulo: Martins Fontes. (Coleção Tópicos). 2008.

FOUCAULT, Michel.

Vigiar e punir: nascimento da prisão. Petrópolis: Vozes. 2007.
FOUCAULT, Michel.

Microfísica do poder. Rio de Janeiro: Graal. 1981.

MAUSS, Marcel.

Uma categoria do espírito humano: a noção de pessoa, a de 'eu'. In: Mauss, Marcel. Sociologia e antropologia. São Paulo: Cosac Naify. p.367-398. 2003.

\section{UNESCO.}

Organização das Nações Unidas Para a Educação, a Ciência e a Cultura. Políticas públicas de/para/com juventudes. Brasília: Ed. CNPq; Unesco. 2004.

\section{UNESCO.}

Organización de las Naciones Unidas Para la Educación, la Ciencia y la Cultura. Comisión Económica Para la América Latina. Centro Latinoamericano y Caribeño de Demografía. Juventud, población y desarrollo: problemas, posibilidades, y desafíos. Santiago: Cepal. 2000. 